(b) The green pyrochrome of the boric acid was unaltered (no soda

(c) The substance floated in the bead in bluish-white, fat-like, amorphous fragments like alumina or opaque silica as tabasheer, but-

(d) On continued heating, the fragments gradually disappeared, leaving bubbles, until in half an hour, with fresh boric acid, there was simply a transparent bead left; exactly the behaviour of minute fragments of diamond in boric acid.

Silica is absolutely, and alumina nearly, insoluble in boric acid before the blowpipe.

One conclusion, therefore, seems this: that a slow solution of charcoal in the water takes place, and that crystals of carbon are deposited upon the aluminium.

London. December, 1878

W. A. Ross

\section{Observations on the Microphone}

WITH regard to an explanation of the action of the microphone I observed a fact which, though it was already known from some anterior experiments with strong galvanic currents, lias not been remarked; as far as I know, with this instrument. On connecting the current from six Grove cells with the micro. phone (the telephone not being: in the circuit) composed of the three carbon rods, the vertical one assumes a vibratory motion between its supports, which canses a very audible sound, especially when placed on a sounding-board.

I think this experiment may serve as another illustration of the well-known fact, discovered by Ampère, of the repulsive action between the subsequent parts of a rectilinear current. Most of the experimental proofs bearing on this point leave soine doubt as to a true demonstration, because a dilatation from the heating effect of the very strong currents used with metallic bodies may interfere, and are considered, for example, to explain the experiments of Furbes and Gore. ${ }^{x}$ But in my case, with a substance which has a very small coefficient of dilatation, I think the vibratory motion may be considered as an electrodynamic effect. As a supporting demonstration, I suspended with insulated metallic wires near another, three horizontal pieces of carbon $(3 \mathrm{~cm}$. long) in such a way that they could move freely away, and the two outer ones were connected with a battery of twenty Grove cells; innmediately on closing the circuit a repulsion ensued between them and an oscillating motion set in, whilst bright sparks appeared between the contacts.

This experiment may throw some light on a recent controversy which has arisen between Mr. Varley and Prof. Hughes. ${ }^{2}$ The latter insists on a change in contact resulting from alternating varying forms of the wolecules or their spheres of action, in accordance with the sonorous vibrations. Mr. Varley points out a quite distinct cause. By using a contact-breaker moved with the hand he discovered, on applying a microscope with a $35^{\circ}$ times magnifying power when the circuit was closed or opened, a grey cloud issuing between the nearest carbon-points. This seems to prove that little particles of carbon are loosened by an effect of trituration on the contact-surface, the cohesion being lessened by the heating effect of the current. This cloud of microscopic dust serves as a vehicle to the current (when the carbon piece is vibrating), and its resistance of course is easily modified by the impinging sound-vibrations. Norw my experiment, though with a strong current, supports this fact, and shows that the vertical carbon is actually vibrating under its influence, and may prepare the above-mentioned condition, or at least render it very ready to change its contact in accordance with sound-waves acting on it with more or less force.

Perhaps it will be observed that a microphone acts very well in transmitting sound when even the weak current from a couple of Leclanché cells is used, but then, also, we may admit a propensity (through the influence of this current) of the vertical carbon rod to get into a vibratory condition, which the sonorous vibrations will easily actuate according to their own period, if really it is not already vibrating at microscopical distances.

Prof. Hughes alludes to an experiment which, as be thinks, gives an evident support to his theory. In a sealed glass tube are inclosed five loose pieces of carbon with terminals to admit a current. He remarks that, properly pressed mere mechanical shaking produces no variation of the current except that due to a constantly increasing resislance caused by abrasion of the carbon contacts, whilst under the influence of sonorous vibrations a varying current is produced, because the tube in this case is

I Forbes, Phil. Mag., t. xvii: p. 358 . Gore; ibid, t. xv. p. sig.

2 Telegraphic foum rnat, October $x$ and $15, \mathbf{i} 878$. varying its length, and the molecules undergo proportional change of form. I think this proof may be as well, and with more probability explained by the facts mentioned above. The tube contains four or five loose pieces of carbon, and besides these some air, which, as it is in a closed space, will press from all sides on the carbon parcels when it is put in vibration by sound, and therefore alter in a mechanical way their distances, the more because the surfaces in contact are rough ones. In conclusion I will observe that the audible vibration of the vertical carbon rod in the microphone certainly elucidates the facts discovered by Blyth concerning sound transmitted only with coal cinders forming a receiving and a transmitting apparatus in a galvanic circuit, and on which he insists in a recent communication to this journal (NATURE, vol. xix. p. 72).

The Hague, December 8,1878

L. BLEEKRODE

\section{Shakespeare's Colour-Names}

IN the name of scientific accuracy and fair criticism I protest against Mr. Murphy's letter in NATURE, vol. xix. p. 197. His remarks proceed on the perfectly gratuitous assumption that all eagles have blue eyes. As this is not a fact (the only live ones I have examined had both of them green eyes), I have no hesitation in asserting that when Shakespeare wrote "An eagle, madam, hath not so green, so quick, so fine an eye as Paris hath," he did so, after having seen an eagle or eagles, and that when he said green he "evidently" meant green, and not blue.

Edinburgh, January 4

A. Craig-Christie

Your correspondent, Mr. J. J. Murphy, in his letter, NATURE, vol. xix. p. I 97 , overlooks the fact that blue is quite as inappropriate as green to describe the eye of an eagle. Shakespeare would never have used either epithet; the word he made use of was doubtless keen. Green has been substituted by the mistake of some transcriber of the play working by ear, and not by eye. I only wonder the correction has not been made long ago by some commentator.

Exeter, January 4

ROBERT BREWIN

\section{The Meteor Shower of January 2}

AFTER a very heavy fall of rain, sleet, and then snow (equalling in the aggregate $I^{\circ} 47^{2} \mathrm{inch}$, on the evening and night of January $I$, the clouds partly cleared away on the ensuing morning, and during a watch of twenty minutes $(6.14$ to 6.34 A.M., January 2) in a sky fully two-thirds overcast, fourteen meteors were seen, all of them belonging to the special shower in Quadrans. This radiant was evidently very active at the time $I$ saw it, and in a cloudless sky, must have supplied meteors at the rate of more than one per minute (for one observer). The paths were stiort and quick without streaks or trains. Radiant point at $230^{\circ}+51^{\circ}$, but not very exactly found owing to the clouds and haze through which several of the meteors were indistinctly seen. Three or four were as bright as Ist mag. stars. W, F. DENNING

Ashleydown, Bristol, January 2

\section{OUR ASTRONOMICAL COLUMN}

MISSING NEBULA.-In Mr. Ellery's Report, to which reference was made last week, it is stated that "two nebulæ, $H_{4223}$ and $H_{156 r}$, widely separated from each other, and described by Herschel as prominent objects, cannot now be found, although careful search has been made for them." The first of these nebulæ is near the cluster Dunlop 4I 3 : in the "General Catalogue" it is called "a remarkable object," but being very large and faint, it might, perhaps, be suspected that its invisibility in the Melbourne reflector is owing to the same cause that has led to the Pleiades-nebula, and other similar diffused objects (as. G. C. I 32,4570 , 5051) being overlooked in very large telescopes though obvious in much smaller ones. But in the case of H $156 \%$ no such supposition is admissible. It was observed by Sir John Herschel on five occasions, in sweeps made between December, I834, and February, 1836; when best seen it was termed pretty bright, from $25^{\prime \prime}$ to $35^{\prime \prime}$ in diameter, gradually brighter towards the centre, and situate to the south of, though very near to, three stars of the eleventh 